\title{
Another Way to Use the Laryngeal Mask Airway (LMA)
}

\author{
James Smit, Dennis E. Feierman \\ Department of Anesthesiology, Maimonides Medical Center, Brooklyn, NY, USA \\ Email:dfeierman@maimonidesmed.org
}

Received 7 March 2016; accepted 18 April 2016; published 21 April 2016

Copyright (C) 2016 by authors and Scientific Research Publishing Inc.

This work is licensed under the Creative Commons Attribution International License (CC BY). http://creativecommons.org/licenses/by/4.0/

c) (i) Open Access

\begin{abstract}
The laryngeal mask airway (LMA) has changed airway management. Besides its use as an airway conduit, it is also used to help obtain a secure airway, i.e., it is used to facilitate the placement of an endotracheal tube. We describe a new technique to use in potential difficult pediatric airway.
\end{abstract}

\section{Keywords}

\section{LMA, Pediatric, Airway}

\section{Introduction}

The supraglottic airway has changed airway management for anesthesiologist and many first responders. It has been incorporated into the difficult airway management [1]. Additionally, for a difficult airway that needs a defined intubation, the laryngeal mask airway (LMA) can act as a conduit for fiberoptic endotracheal intubation [2]. However, the ETT might be too short to ensure that the inflated ETT cuff will lie below the vocal cords [3]. This technique often requires use of another uncuffed endotracheal intubation to push the lead endotracheal tube through the cords. It has been suggested to cut the shaft of the disposable LMA to avoid this problem [4]. In the small baby, passing the pilot tube through the LMA can be difficult. Additionally, using the LMA as the conduit adds potential unfavorable possibilities for the child such as disruption of ventilation. Additionally, the LMA may not always overlie the cords correctly, and during extraction of the LMA, the ET tube risks being displaced or completely pulled out of the trachea. We report on an additional method for using the LMA in a potentially difficult pediatric airway which attempts to avoid these risks.

\section{Case}

A 3-year old 14 kg male child with Down syndrome presented for dental restoration under general anesthesia. 
This was his first exposure to anesthesia and there was no family history of problems with anesthesia. There was no other significant medical history. Physical exam was significant for poor dentition, a very protruding large tongue and was a potential difficult intubation. The plan was to maintain spontaneous ventilation. Anesthesia was induced with $8 \%$ sevoflurane in $100 \%$ oxygen and the child was keep spontaneously breathing. A LMA \#2 was introduced into the airway without difficulty. The LMA was connected to the circuit, ETCO2 and tidal volumes where adequate and a $22 \mathrm{~g}$ IV was placed. Eight $\mathrm{mcg} / \mathrm{kg}$ of glycopyrrolate was given to dry secretions and attenuate the bradycardia frequently seen in Down syndrome children [5]. Anesthesia was maintained with 6\% sevoflurane. After gentile preparation of both nares with mild strength neosynephrine solution, a pediatric fiberoptic scope (2.5 minimum endotracheal tube) loaded with a number 4 cuffed endotracheal tube, was introduced into the right naris and advanced until the edge of the LMA was observed (Figure 1). An assistant simply pulled the LMA back into the mouth revealing the open cords in front of the advancing scope (Figure 2). The fiberoptic which easily passed between the cords until the carina was visualized and the ET tube was advanced over the fiberoptic scope into the trachea. After the ET tube was connected to the circuit and a suitable CO2 tracing verified the LMA was simply removed.

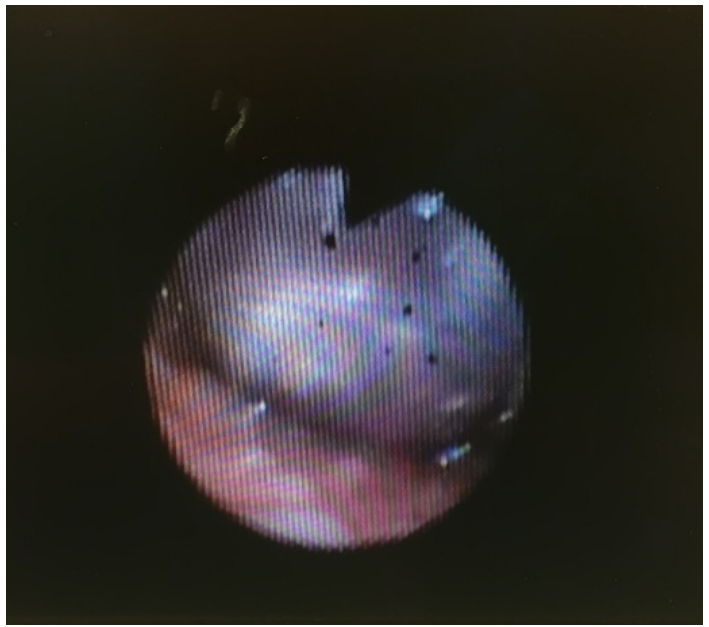

Figure 1. The fiberoptic was placed in the right naris and advanced towards the trachea. Picture of the LMA (blue, center) as seen through a pediatric fiberoptic scope. The patient was maintained on $6 \%$ sevoflurane and spontaneously breathing.

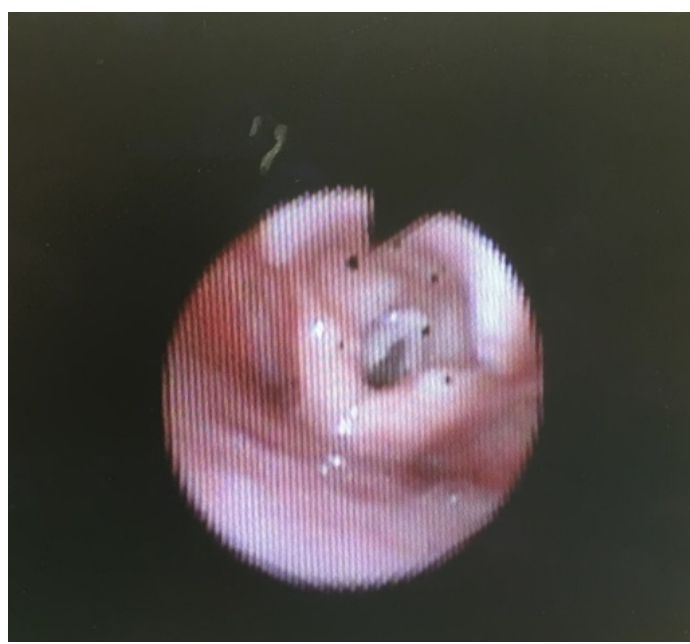

Figure 2. Picture seen through a pediatric fiberoptic scope immediately after the assistant removed the LMA. The scope was easily advanced into the trachea and a 4.0 cuffed ETT was treaded over the scope. The patient was maintained on $6 \%$ sevoflurane and spontaneously breathing throughout the entire procedure. 


\section{Discussion}

There are many ways to approach a potential difficult airway. Pediatric difficult airway can be even more challenging especially in children that have special needs. Maintaining spontaneous ventilation leaves a good exit plan in the event that the airway cannot be secured. This technique needs an additional person; however, it can be performed with just an assistant. We believe this technique for intubation of the difficult pediatric airway and especially the airway of the small children since it allows oxygenation and ventilation to be interrupted to the absolute minimum. This technique lends itself to those scenarios when the intubation is not thought to be difficult at outset but a difficult intubation becomes evident after induction and a LMA can and is successfully used. If upon lifting the LMA, the cords are not directly visible in front of the advancing scope and cannot be quickly seen, the LMA is reseated and ventilation resumed so that a second try can occur. To date we have also used this intubating technique on neonates.

\section{References}

[1] American Society of Anesthesiologists Task Force on Management of the Difficult Airway (2003) Practice Guidelines for Management of the Difficult Airway: An Updated Report by the American Society of Anesthesiologists Task Force on Management of the Difficult Airway. Anesthesiology, 98, 1269-1277.

[2] Benumof, J.L. (1996) Laryngeal Mask Airway and the ASA Difficult Airway Algorithm. Anesthesiology, 84, 686-699. http://dx.doi.org/10.1097/00000542-199603000-00024

[3] Asai, T., Latto, I.P. and Vaughan, R.S. (1993) The Distance between the Grille of the Laryngeal Mask Airway and the Vocal Cords. Is Conventional Intubation through the Laryngeal Mask Safe? Anaesthesia, 48, 667-669. http://dx.doi.org/10.1111/j.1365-2044.1993.tb07175.x

[4] Osborn, I.P. and Soper, R. (2003) It's a Disposable LMA, Just Cut It Shorter-for Fiberoptic Intubation. Anesthesia and Analgesia, 97, 299-300. http://dx.doi.org/10.1213/01.ANE.0000067921.62656.B7

[5] Kraemer, F.W., Stricker, P.A., Gurnaney, H.G., McClung, H., Meador, M.R., Sussman, E., Burgess, B.J., Ciampa, B., Mendelsohn, J., Rehman, M.A. and Watcha, M.F. (2010) Bradycardia during Induction of Anesthesia with Sevoflurane in Children with Down Syndrome. Anesthesia and Analgesia, 111, 1259-1263.

http://dx.doi.org/10.1213/ANE.0b013e3181f2eacf 